\title{
O IDOSO NAS INSTITUIÇÕES GERONTOLÓGICAS: UM ESTUDO NA PERSPECTIVA DAS REPRESENTAÇÕES SOCIAIS
}

\author{
Ludgleydson Fernandes de Araújo \\ Universidade Federal do Piauí \\ Maria da Penha de Lima Coutinho \\ Universidade Federal da Paraíba \\ Maria de Fátima de Souza Santos \\ Universidade Federal de Pernambuco
}

\begin{abstract}
RESUMO: Este trabalho teve como objetivo identificar e comparar as representações sociais de velhice entre idosos de Grupos de Convivências (GC's) e de Instituições de Longa Permanência (ILPI's). Participaram 50 idosos (25 dos GC's e 25 das ILPI's), de ambos os sexos (60\% feminina e $40 \%$ masculina), com média de idade de 82 anos. Utilizou-se Entrevistas Semi-Estruturadas, realizadas de forma individual no âmbito das instituições gerontológicas. Os dados foram analisados com apoio do software Alceste (Reinert, 1990) através da Análise Hierárquica Descendente, que permite uma análise das raízes lexicais, considerando a palavra como unidade, também oferece a sua contextualização no corpus. Os dados obtidos emergiram representações em dois pólos antagônicos: por um lado, as vivências relacionadas aos ganhos e, outro, as perdas inerentes à velhice. Verificaram-se representações sociais da velhice numa conotação negativa, e comumente associada ao binômio velhice-doença. Salienta-se a importância de intervenções psicossociais que priorizem a melhoria na qualidade de vida do idoso.
\end{abstract}

PALAVRAS-CHAVE: velhice; instituições gerontológicas; representações sociais.

\section{THE ELDERLY IN GERIATRIC INSTITUTIONS: A STUDY FROM THE PERSPECTIVE OF SOCIAL REPRESENTATIONS}

ABSTRACT: The objective of this work is to identify and compare social representations of old age among elderly people from Socializing Groups (SG's) and Long-Permanence Institutions (LPI's). A number of 50 elderly people have participated ( 25 from SG's and 25 from LPI's) from both genders (male $-40 \%$, and female $-60 \%$ ), with an average of 82. Semi-Structured Interviews have been carried out individually inside geriatric institutions. It was processed by Alcest software (Reinert, 1990) through a Descendant Hierarchical Analysis which makes possible to analyze the lexical roots, considering the word as a unit, it also offers the context of the word in the corpus. Data obtained showed representations in two antagonistic poles: on the one hand there are the experiences related to gains and on the other hand the losses inherent to old age. Social representations of old age on a negative connotation and commonly associated to the binomial old age-sickness were verified. The importance of psychosocial interventions, which priority is to increase the quality of life of the elderly, was pointed out.

KEYWORDS: old age; geriatric institutions; social representations.

A questão do envelhecimento e da longevidade humana é algo que já se fazia presente na mais remota história, seja como busca pela fórmula da eterna juventude, associada à felicidade plena, ou como preocupação constante do homem em todos os tempos. Na última déca$\mathrm{da}$, tal questão vem despertando maior interesse social e cien-tífico, sobretudo devido ao crescente envelhecimento popu-lacional que vem ocorrendo tanto no âmbito mundial, co-mo no Brasil (Beltrão \& Camarano, 2002).

Segundo a Organização Mundial de Saúde - OMS (2005), o Brasil será o sexto país com maior número de pessoas idosas até 2025 , o que torna urgente a necessidade de investigações que contribuam para melhoria e/ou manutenção da saúde e qualidade de vida nessa faixa etária, considerando, principalmente, que este crescimen- to provoca mudanças na pirâmide etária, que avança em uma proporção geométrica, ao passo que a preparação para esta metamorfose ocorre em proporções aritméticas.

De acordo com a PNAD - Pesquisa Nacional por Amostragem de Domicílios (2003), a população a partir de 60 anos ou mais representa $9,6 \%$ da população total. $\mathrm{O}$ aumento no número de idosos na população brasileira é algo presente nas projeções demográficas, isto devido, sobretudo, aos avanços sócio-sanitários e ao aumento da longevidade.

Para designar os conceitos que fazem referência à população de idades avançadas, há um consenso entre os pesquisadores das diversas áreas do conhecimento de que apenas o critério etário não é suficiente para demarcar o último curso da vida, que antecede à morte (Debert, 1999; Gómez, 2002). Tal fenômeno é diferencial e obedece a 
uma gama de fatores, tanto endógenos, como exógenos, nas esferas social, histórica, cultural, fisiológica e psicológica (ver Neri, 2002).

Até o século XIX, a velhice era tratada como uma questão de mendicância, porque sua fundamental característica era a não possibilidade que uma pessoa apresentava de se assegurar financeiramente. Assim, a noção de velho remete à incapacidade de produzir, de trabalhar. Dessa forma, segundo Peixoto (1998), era denominado velho (vieux) ou velhote (veillard) aquele indivíduo que não desfrutava de status social - muito embora, o termo velhote também fosse utilizado para denominar o velho que tinha sua imagem definida como bom cidadão.

Para demonstrar uma visão menos estereotipada da velhice, o termo idoso foi adotado para caracterizar, tanto a população envelhecida, em geral, como aquela mais favorecida. A partir de então, os "problemas dos velhos" passaram a ser vistos como "necessidades dos idosos" (Peixoto, 1998). Por outro lado, Neri e Freire (2000) colocam que a substituição dos termos velho ou velhice por melhor idade, terceira idade, já indica preconceito, pois, caso contrário, essa troca de palavras não seria necessária.

Há ainda outras metáforas acerca do envelhecimento, como, por exemplo, amadurecer e maturidade, que significam a sucessão de mudanças ocorridas no organismo e a obtenção de papéis sociais, respectivamente (Neri \& Freire, 2000). Considerando os mais variados termos, de distintos autores, sobre a questão da velhice, percebe-se que a pessoa envelhecida conheceu, assim, uma série de modificações ao longo do tempo, uma vez que as mudanças sociais reclamavam políticas sociais para a velhice, assim como a construção ética do objeto velho (Peixoto, 1998).

Todavia, mesmo com a existência de inúmeros termos para denominar a fase da vida de 60 anos ou mais, não se deve negar que a velhice - ou qualquer outro termo que se use - constitui uma fase do desenvolvimento humano tão importante quanto as demais, merecendo, portanto, toda a atenção e dedicação, tanto dos estudiosos do assunto, quanto da família, da sociedade, e, principalmente, do Estado, através do planejamento e operacionalização das políticas públicas para velhice.

A velhice constitui uma temática recente no âmbito da Psicologia, de um modo geral, e na Psicologia Social, em particular. No entanto, ao longo das últimas décadas têm crescido significativamente as pesquisas junto a este grupo social, demonstrando a importância da compreensão deste objeto a partir da ótica biopsicossocial.

A história das representações sociais (RS) insere-se na inter-relação entre atores sociais, o fenômeno e o contexto que os rodeia. Dessa forma, tais representações têm implicações na vida cotidiana e nos comportamentos adotados por um grupo de indivíduos acerca de um objeto, que são resultantes do modo como os atores sociais re- presentam socialmente esse objeto e do significado que estes adquirem em suas vidas.

Para Doise (1990), a utilização da teoria das representações sociais é bastante útil, na medida em que se lida com um marco conceitual que envolve tanto o nível intrapessoal de análise quanto o interpessoal e o intergrupal; desta forma, é possível partir das representações de objetos sociais para um exame das cognições no nível grupal, que permitem ao pesquisador a apreensão dos aspectos compartilhados de uma representação.

A representação social é vista como um processo público de criação, elaboração, difusão e mudança do conhecimento compartilhado no discurso cotidiano dos grupos sociais (Doise, 1990; Jodelet, 1989, 2001; Moscovici, 2001, 2003), e será utilizada no desenvolvimento deste estudo, que vê $a$ "representação social compreendida como a elaboração de um objeto social pela comunidade com o propósito de conduzir-se e comunicar-se" (Moscovici, 2003, p. 251).

Segundo o pensamento de Moscovici (1961), toda representação surge da necessidade de transformar o que é estranho, o que não é compreendido, em algo familiar. Essa seria uma das funções principais da representação: "domar o desconhecido". Em geral, os grupos produzem representações também como uma forma de filtrar a informação que provém do ambiente. É um tipo de manipulação do processo do pensamento e da estrutura da realidade psicossocial.

Neste sentido, estudar as representações sociais da velhice no contexto dos Grupos de Convivências (GC) e Instituições de Longa Permanência (ILPI) à luz desta teoria passa necessariamente pela apreensão de um conhecimento compartilhado, viabilizado na interação entre o saber do senso comum e o saber científico. Assim, o presente trabalho tem como objetivo apreender e comparar as representações sociais da velhice no âmbito de ILPI's e GC's para idosos na cidade de João Pessoa-PB.

\section{Método}

\section{Participantes}

A amostra foi constituída por 50 idosos escolhidos de forma não-probabilística, intencional e acidental (sendo 25 de Grupos de Convivência e 25 de Instituição de Longa Permanência), com idade variando entre 60 a 95 anos $(X=82$, $\mathrm{DP}=3,75), 40 \%$ do sexo masculino e $60 \%$ feminino. É válido salientar que idosos dos Grupos de Convivência fazem parte do Programa de Atenção ao Idoso da Prefeitura Municipal da cidade de João Pessoa - PB. O outro grupo pesquisado é formado por idosos de Instituições de Longa Permanência, em sua maioria de caráter filantrópico. Faz-se necessário mencionar que tal escolha ocorreu com o intuito de comparar as representações acerca da velhice entre os grupos de convivências e de Institui- 
ções de Longa Permanência, considerando-se que as diferenças grupais podem contribuir para a construção de representações sociais diversas. A participação tinha como pré-requisito pertencer a grupos de idosos a pelos menos oito anos e possuir 60 anos ou mais, pois, de acordo com dados da ONU (Organização das Nações Unidas), é considerado velho, em países em desenvolvimento como o Brasil, quem tem idade a partir de 60 anos. Os participantes dispunham de livre escolha para participar ou não da presente pesquisa.

\section{Instrumento}

O roteiro de entrevista, utilizado nos dois grupos de idosos pesquisados, contemplou em sua primeira parte dados sócio-demográficos (sexo, idade, escolaridade, tempo em que reside na instituição, estado civil, dentre outros) e, em sua segunda parte, a questão norteadora: Para o(a) senhor(a), o que representa a velhice? Vale salientar que esta questão foi elaborada tendo por base o estado atual da arte, bem como os objetivos da presente pesquisa.

\section{Procedimentos para coleta dos dados}

Inicialmente, o projeto foi enviado ao Comitê de Ética em Pesquisa com seres Humanos do CCS (Centro de Ciências da Saúde) da UFPB, com o intuito de averiguar os parâmetros éticos, tendo como base as resoluções no 196/96 do Conselho Nacional de Saúde e a $\mathrm{n}^{\circ} 16 / 2000$ do Conselho Federal de Psicologia, recebendo parecer de aprovação para realização da pesquisa, uma vez que sua operacionalização, de acordo com o parecerista, não traria nenhum dano à saúde física e/ou psíquica dos participantes. Posteriormente, solicitou-se a autorização das coordenações dos grupos de convivência, das instituições de longa permanência e dos idosos, objetivando a realização da pesquisa.

\section{Coleta de dados da entrevista}

Utilizou-se o critério estabelecido por Camargo (2005) para definição do número de entrevistas a serem realizadas entre os participantes desta pesquisa, o qual estabelece a partir de 20 unidades de contexto inicial (u.c.i) ou entrevistas de cada grupo quando se trata de um estudo comparativo para ser analisado no programa de dados textuais Alceste. Neste trabalho, foram realizadas 50 entrevistas em seu total, das quais 25 foram com idosos de ILPI's e outras 25 com idosos de GC's.

As entrevistas foram realizadas de forma individual, em salas que, no momento, não estivessem com atividades no âmbito das instituições geriátricas, com o intuito de não prejudicar a qualidade do material gravado; e permitindo que o entrevistado verbalizasse o tempo que fosse necessário. Inicialmente, os idosos foram contatados pelo pesquisador, levando-se em consideração que, para sua participação, fazia-se necessário possuir sessenta anos ou mais, e ser participante do grupo de convivências ou instituições de longa permanência. Após explicitado o objetivo da pesquisa, apresentou-se o termo de consentimento livre esclarecido, que garante a preservação da identidade e anonimato dos sujeitos, uma vez que se fez necessária a gravação da entrevista.

\section{Procedimentos para análise dos dados}

Para análise dos dados apreendidos através da entrevista, utilizou-se o software ALCESTE (Análise Lexical por Contexto de um Conjunto de Segmentos de Texto) em sua versão 4.5, que foi desenvolvido na França por M. Reinert (1990, 1986). O referido programa, além de permitir uma análise lexical quantitativa que considera a palavra como unidade, também oferece a sua contextualização no corpus ou entrevista.

Cada entrevista é composta por conteúdos semânticos, que formaram o banco de dados ou corpus analisado pelo Alceste. Realizou-se uma Análise Hierárquica Descendente, que permite a análise das raízes lexicais e oferece os contextos em que as classes estão inseridas de acordo com o segmento de textos do corpus da pesquisa (Camargo, 2005).

O Alceste é uma técnica de análise de dados textuais que possibilita a exploração da estrutura e organização do discurso dos atores sociais, bem como permite o acesso às relações entre os universos lexicais que, possivelmente, seriam difíceis de identificar com o uso da análise de conteúdo tradicional (Alba, 2004).

Inicialmente, foi formatado o banco de dados das entrevistas seguindo o modelo proposto por Camargo (2005), cujas etapas operacionais serão descritas a seguir:

- As entrevistas realizadas com os idosos foram gravadas mediante a permissão dos mesmos e posteriormente transcritas;

- Cada entrevista é composta por conteúdos semânticos, de acordo com o banco de dados ou corpus a ser analisado pelo ALCESTE. Para formatação do corpus, foi realizado um único arquivo digitado no Word for Windows 2000, salvo no tipo texto-txt. As linhas de comando são digitadas sempre antes de cada conteúdo semântico da entrevista, com o intuito de separar cada Unidade de Contexto Inicial (UCI), que diz respeito às respostas que os atores sociais mencionaram frente à pergunta norteadora. Nas linhas de asteriscos ou de comando são digitadas as variáveis descritivas (sexo, instituição geriátrica, idade, dentre outras). É válido salientar que as etapas operacionais do Alceste serão mencionadas com riqueza de detalhes, uma vez que apesar do software ser bastante empregado em pesquisas no âmbito da Psicologia Social, ainda há um desconhecimento acerca da sua utilização e operacionalização (Alba, 2004).

Após a formatação do corpus, segue a análise no software Alceste, que envolve quatro etapas operacionais: Etapa A: Leitura do Texto e Cálculo dos Dicionários; 
Etapa B: Cálculo das Matrizes de Dados e Classificação das UCE's; Etapa C: Descrição das Classes de UCE's; Etapa D: Cálculos Complementares (ver Camargo, 2005).

É válido ressaltar que o software Alceste tem contribuído de forma significativa nos estudos das RS na realidade brasileira, tendo em vista que possibilita uma interpretação de um volume considerável de dados textuais, bem como a possibilidade da triangulação de dados qualitativos e quantitativos.

\section{Resultados e Discussão}

A análise dos resultados constituída pelo corpus de 50 unidades de contexto inicial (u.c.i.), ou entrevistas, e processados pelo software Alceste apresentou uma divisão do corpus em 244 unidades de contexto elementar (u.c.e.), contendo 1531 palavras, formas ou vocábulos distintos. Vale salientar que, seguindo critério estabelecido pelo Alceste, foram desconsiderados do corpus de análise os vocábulos que possuíssem uma freqüência inferior a 3 , posto que concerne ao critério estabelecido no cálculo do $X^{2}$ (palavras com frequiência maior que 3, conseqüentemente, com $\mathrm{X}^{2}$ a partir de 3,84 é significativo com 1 grau de liberdade).

Assim, após a redução dos vocábulos às suas raízes lexicais, verificou-se que das 1531 palavras, 344 eram analisáveis e 19 palavras instrumentos (no total foram 363 palavras). É válido salientar que as 344 palavras analisáveis ocorreram 6653 vezes. Foram divididas as 244 u.c.e. do corpus analisado, no qual se obteve 112 u.c.e., correspondendo a $45,9 \%$ do total, ou seja, foram descartados $54,1 \%$ das demais.

O Dendrograma 1 diz respeito à distribuição das quatro classes das Representações Sociais da Velhice apreendidas nos dois grupos de idosos pesquisados (GC's e ILPI's).

Neste Dendrograma, observa-se o título de cada uma das classes, seguido pelo número de u.c.e. que a compõe, a descrição da classe, bem como as variáveis descritivas e as palavras de maior associação com a referida classe, levando-se em consideração o coeficiente obtido no teste de associação $X^{2}$.

Destaca-se que as representações sociais da velhice neste Dendrograma 01 estruturaram-se em dois campos representacionais, a saber: o primeiro foi construído pelas classes 1 e 4 que correspondem às Vivências Divergentes na Velhice: suas Perdas e Ganhos. No que tange ao segundo campo, este foi estruturado pelas classes 2 e 3 que dizem respeito às Vivências Relacionadas às Conquistas Sócio-Afetivas e Comportamentais advindas dos GC's.

Assim, serão discutidas as classes que estruturam o Dendograma 01 , tendo em vista as u.c.e. encontradas em cada classe.

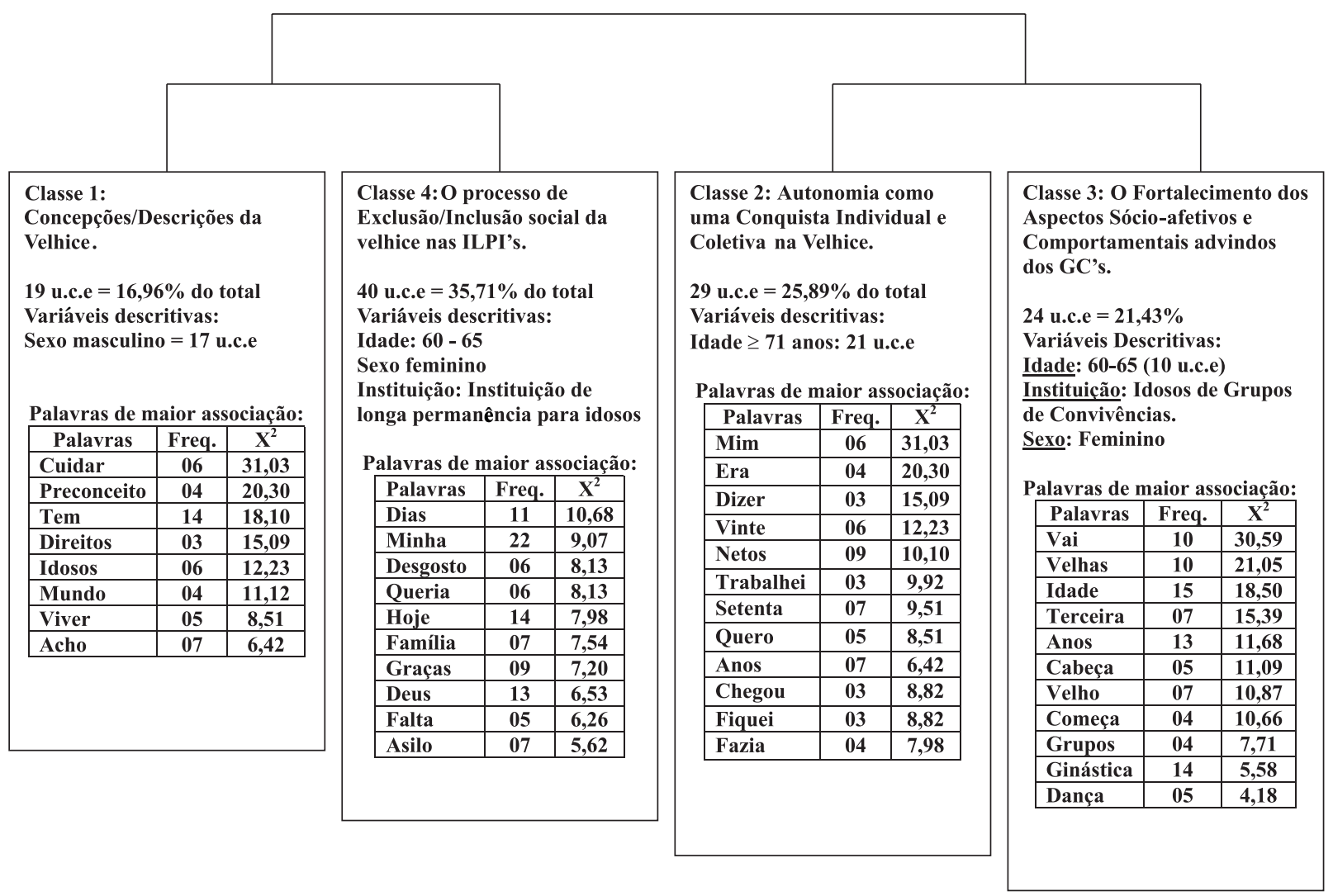

Dendograma 1 - Distribuição das classes nas representações sociais da Velhice - Grupo de Idosos das ILPI's e GCI's (n = 50). 


\section{Vivências divergentes na velhice: suas perdas e ganhos (Classes 1 e 4)}

O campo das perdas reúne tanto as dificuldades enfrentadas pelos idosos no âmbito das relações sociais e os ganhos advindos das conquistas sociais da implementação de algumas políticas públicas direcionadas à velhice:

\section{Classe 1: concepções/descrições da velhice}

De acordo com o número de u.c.e. que estrutura esta classe (19 u.c.e. - 16,96\% do total), salienta-se que a mesma é considerada a classe com menor poder explicativo deste dendrograma entre os idosos pesquisados.

Levando-se em consideração as variáveis descritivas, pode-se caracterizá-la como uma classe que foi constituída majoritariamente por idosos do sexo masculino de ambas instituições geriátricas (17 u.c.e.).

Percebe-se ainda na classe 1 uma predominância de conteúdos concernentes às dificuldades e conquistas sociais relacionadas à velhice, uma vez que as palavras que obtiveram maior associação com a classe foram: cuidar/ cuidados, preconceito, tem, direitos, idosos, mundo, viver, acho, gostaria. Os conteúdos lexicais mencionados pelos idosos dizem respeito à demanda de cuidados como característica da velhice, ressaltando as atitudes preconceituosas frente à pessoa idosa, como pode ser verificado nas u.c.e. mais típicas desta classe:

assim não tenho muito problemas (...) mas você sabe que ainda tem muito preconceito para com idoso (...), mas isso tem melhorado muito ultimamente, nós já temos alguns direitos como fila, passagem livre em ônibus (...), e ainda tem muitas pessoas que respeitam o idoso (...), (...) uma pessoa para cuidar do idoso (...), porque se deixar o idoso sozinho ele não pode fazer nada (...), porque ele não pode ficar só (...). E viver bem a velhice, de forma tranqüila, conversando com as pessoas (...), tem que ter paciência (...) tem que ter uma pessoa para cuidar dele todos os dias (...), eu acho assim, o idoso tem que ter uma pessoa para cuidar do idoso (...), pois é uma coisa que merecem cuidados, tem que ter uma enfermeira, um médico também ao lado (...) (Entrevista 23, Idoso de GC's).

Pode-se observar neste agrupamento que há dois pólos representacionais que contribuíram para a formação das RS dos idosos pesquisados: por um lado, às dificuldades que estes encontram nas relações interpessoais da vida cotidiana e, por outro, as conquistas que os idosos mencionam advindas da implementação de políticas públicas focalizadas nestes atores sociais.

Verificou-se que os idosos desta pesquisa mencionaram as atitudes preconceituosas como algo presente na sociedade contemporânea, na qual a velhice é apresentada como um problema social, tendo em vista que esta se transformou num perigo, em uma ameaça à vida em sociedade, devido aos custos do Estado e da família com os idosos relativos à saúde, previdência, dentre outros (Araújo, 2006; Debert, 1998, 1988; Kalache \& Keller, 2000).

De acordo com Rodríguez (1996), o significado da noção de envelhecimento, de velho e de velhice não é algo definitivo, estruturado para sempre, nem para os grupos sociais, nem para o sujeito individual, uma vez que o sentido e o significado concernentes a estes construtos são resultados de uma recorrente construção social e histórica. A construção da velhice ocorre nas relações sociais, nos interesses ideológicos e até econômicos.

Desse modo, observa-se que os elementos negativos acerca da velhice são construídos ao longo dos tempos nas relações intra e intergrupos. Nesse sentido, Hewstone (2001) salienta que muitas explicações do senso comum poderiam ser o resultado de uma transformação das explicações científicas, sendo no mínimo tão importante conhecer como o saber social é transformado, quanto como a informação é tratada pelos indivíduos pertencentes a determinado grupo social.

É importante mencionar que as atitudes de discriminação em relação à velhice por vezes são expressas através de reações de afastamento, desgosto e ridicularização, de modo que, ainda na sociedade contemporânea, o velho é visto como uma pessoa incapaz e inútil (Neri \& Freire, 2000). Tais elementos de cunho preconceituoso estão presentes na construção e elaboração das representações sociais entre os idosos pesquisados.

Um fato que merece destaque nesta classe concerne às questões relacionadas aos "cuidados" inerentes à velhice. Vale salientar que esta classe foi constituída de forma majoritária por idosos (sexo masculino), é razoável inferir que tal representação deve-se ao fato de existir o componente cultural que atribui à mulher os cuidados familiares em geral.

$\mathrm{O}$ cuidado familiar é freqüentemente atribuído às mulheres, este fato por vezes contribui para desvantagens cumulativas em relação aos homens, de modo que essas tendem a ser mais pobres (em virtude de não exercer atividades remuneradas e, conseqüentemente, haver uma dependência econômica, em geral do cônjuge) e a apresentar mais deficiência em idades mais avançadas (possuem maior esperança de vida, o que pode acarretar o surgimento de doenças crônicas e degenerativas) (OMS, 2005).

Quanto às conquistas sociais, fruto das reivindicações dos gerontes e da sociedade civil organizada através das políticas sociais para a velhice implementadas na Política Nacional (Lei no 8.842 de 04/01/1994) e no Estatuto do Idoso (Lei $\mathrm{n}^{\circ} 10.741$ de 01/10/2003), estas foram bastante significativas para os idosos, pois algumas melhorias, como fila preferencial em bancos, repartições públicas e privadas; passe livre nos ônibus urbanos, prioridade nos processos jurídicos, dentre outras, contribuíram para que os 
velhos pudessem ocupar seu papel de cidadão com ações positivas frente à velhice.

Assim, urgem ações que priorizem os cuidados básicos e atenção integral aos gerontes, que possam contribuir para que este desenvolva mecanismos de enfrentamento das limitações ocasionadas pelo envelhecimento normal ou patológico, aumentando conseqüentemente o bem-estar biopsicossocial nesta fase do desenvolvimento humano (velhice).

\section{Classe 4: o processo de exclusão/inclusão social nas ILPI's}

Esta classe foi estruturada com 40 u.c.e., representando 35, 71\% do total. Ressalta-se que esta é a classe de maior poder explicativo deste Dendrograma 1. No que tange às variáveis descritivas, a classe 4 é formada por idosos do sexo feminino de Instituições de Longa Permanência, na faixa etária dos 60-65 anos (com 10 u.c.e.).

As palavras de maior associação a esta classe referemse ao processo de exclusão/inclusão social do idoso em instituições geriátricas, a saber: dias, minha, desgosto, queria, hoje, família, graças, Deus, falta, asilo, conforme se pode perceber, de acordo com as unidades de contexto elementar (u.c.e.) que mais caracterizam esta classe 4, nos conteúdos semânticos a seguir:

\begin{abstract}
A Velhice não me preocupa (...), pois a gente só vive até a data que Deus quiser (...), a gente fica velhinho é porque Deus quis (...), se a gente morre nova foi porque Deus quis (...), então eu gosto de minha velhice (...) O único desgosto que eu tenho não é de ter chegado a idade (...), o desgosto que eu tenho é da discriminação, o desprezo (...), é esse o desgosto que eu tenho (...), eu não tenho desgosto da velhice, não (...) eu acho que vou terminar meus dias só na companhia do Senhor (...) num canto meu (...) são estes os meus projetos, porque eu gosto muito de estar no meu canto, o asilo é apenas uma passagem na minha vida (...) (Entrevista 18, Idoso de ILPI's).
\end{abstract}

Pode-se verificar na presente pesquisa que as ILPI's desempenham um papel importante na sociedade, por oferecerem aos idosos que não possuem familiares um espaço de construção de novas relações, de troca afetiva. No entanto, faz-se necessário refletir sobre as questões que contribuíram para o surgimento na sociedade de tais instituições que "acolhem" os marginalizados, tendo em vista que o recente Estatuto do Idoso prescreve que cabe à Família, ao Estado e à Sociedade o dever de oferecer condições dignas para as pessoas idosas, realidade não comumente encontrada nas instituições geriátricas.

As instituições de Longa Permanência, se, por um lado desempenham seu papel de acolhedora dos velhos em processo de exclusão social, por outro lado, suas normas internas contribuem para o afastamento dos problemas sociais externos, proporcionando um confinamento social, na medida em que restringe a vida do idoso apenas à vida asilar, caracterizando-se como uma forma de ruptura dos elos que os ligavam à vida familiar e social (Alcântara, 2004; Santos, 1994, 1997, 2000).

De acordo com Santos (1994), ainda persiste a idéia de que o velho é uma sobrecarga para a família. A limitação do espaço físico das habitações, as dificuldades de dedicação permanente aos velhos e a inserção da mulher no mercado de trabalho, que a impede de exercer o papel que lhe é tradicionalmente atribuído, de cuidadora das crianças e idosos, motivam os familiares a colocar os idosos nas ILPI's, excluindo-os do convívio sócio-afetivo e familiar.

Um fato que também merece destaque diz respeito à atribuição divina como forma de esperança, responsabilidade ou naturalização da inserção do idoso nas ILPI's, fato também verificado em pesquisa realizada entre idosos de instituições geriátricas paraibanas (Araújo, Coutinho \& Saldanha, 2005; Araújo, Coutinho \& Santos, 2006). Infere-se que tal fato seja uma forma de poder resolver a dissonância resultante do abandono sócio-afetivo e familiar. Os idosos institucionalizados desenvolvem diferentes táticas de adaptação ao asilo, podendo utilizá-las de várias formas ao mesmo tempo nas relações interpessoais (Goffman, 1987).

É razoável salientar que, de forma antagônica, existem pesquisadores na área do envelhecimento humano (ver Graeff, 2005), partem da premissa que a institucionalização na velhice está passando por uma redefinição do seu papel na sociedade, de modo que os asilos podem possibilitar aos idosos relações interpessoais saudáveis, ressignificação de suas trajetórias de vida e a vivência de uma dignidade na velhice no âmbito de instituições de longa permanência.

Para Debert (1999), o termo asilo adquire uma conotação pejorativa na sociedade contemporânea, sendo intrínseco aos estereótipos negativos, de modo que são formulados eufemismos como: Lar dos Velhinhos, Jardim ou Casa de Repouso, com o intuito de diminuir ou substituir a rotulação discriminatória, que possui como pano de fundo a denominação asilo.

\section{Vivências relacionadas às conquistas comportamentais e sócio-afetivas advindas dos GC's (Classes 2 e 3)}

Se, por um lado, a velhice é pensada como período de perda e conformismo, por outro lado, destacam-se alguns ganhos conquistados, seja individualmente, seja a partir da participação coletiva.

Classe 2: autonomia como uma conquista individual e coletiva na velhice 
Observa-se que esta classe obteve 29 u.c.e. com $25,89 \%$ do total. No que diz respeito às variáveis descritivas, estas foram compostas tipicamente por idosos que compreendem a faixa etária maior ou igual a 71 anos com 21 u.c.e.

As palavras de maior associação nesta classe foram: mim, era, dizer, vinte, nada, netos, trabalhei, setenta, quero, anos, fiquei, fazia. Percebe-se que os conteúdos apontam para a ênfase da autonomia como uma conquista individual e coletiva na velhice. Nas representações apreendidas entre os idosos, verifica-se também uma justificativa de um passado (na juventude e na vida adulta) quefoi marcado pela independência, produtividade e autonomia.

Pode-se perceber, de acordo com as unidades de contexto elementar (u.c.e.), as principais características da classe 2 nos conteúdos semânticos a seguir:

olhe pra lhe dizer melhor pra mim a velhice ainda não chegou ainda (...), tenho 70 anos, mas sou jovem (...), danço muito, só não quero namorar, nem casar, mas me divirto bastante, viajo muito (...) eu gosto da minha velhice, eu dou graças a deus eu já estou com setenta e seis anos, olhe eu lavo minha roupinha, eu costuro, faço bordados, eu faço todos os meu serviços, (...) porque eu já trabalhei muito, mas eu não tenho velhice, não tenho isso não (...) eu não gosto muito, porque quando eu era mais nova eu andava (...), eu fazia tudo, eu ia para todo canto e agora eu não estou mais podendo fazer nada (Entrevista 24, Idosos de GC's).

Observa-se nesta classe que os idosos realçam a autonomia individual para justificar a sua não inserção no modelo médico-biológico de velhice (Santos \& Belo, 2000) vigente na sociedade contemporânea, ou seja, uma vez que eles são autônomos e independentes, não estão, portanto, inclusos no grupo das pessoas idosas, dependentes.

Neri (1993) ressalta que o desconhecimento do que significa ser velho induz a práticas com foco ideológico, que contribuem para a manutenção e a propagação de mitos, estereótipos negativos e preconceitos acerca da velhice. Provavelmente, a imagem negativa da velhice verificada entre os idosos pesquisados é devida aos construtos psicossociais e ideológicos a priori mencionados, que permeiam as relações interpessoais e afetivas presentes na atualidade.

Por isso, é bastante comum encontrar nos discursos dos velhos expressões como: "velhice não existe", ou que "velhice é um estado de espírito", ou que "a vida começa aos 40" (Neri \& Freire, 2000). Esta idéia de fato circula na vida cotidiana e pode significar uma autodefesa dos idosos para amenizar o desconforto psicossocial causado pela sua inclusão no grupo de "pessoas velhas".

Assim, a velhice, de modo geral, é vista como uma forma de "autoconvencimento", com a retórica de que as transformações biológicas acontecem, mas, o espírito po- de resistir à velhice, de modo a retardá-la ou oferecê-la uma nova dimensão (Debert, 1988; Santos \& Almeida, 2004). Denota-se entre os velhos o fenômeno da "desnaturalização" da velhice, que depende, sobretudo, de cada indivíduo na forma de vivenciar esta etapa da vida (Araújo, 2006; Araújo, Coutinho \& Santos, 2006).

De acordo com Moscovici (2003, 2001), para as RS existem duas questões que são os fios condutores, quais sejam: a comunicação e a ideologia, do ponto de vista da sua estrutura, da sua gênese e da sua função. Neste sentido, os componentes ideológicos intrínsecos à comunicação intra e intergrupos na sociedade contemporânea acerca da velhice expressos de forma negativa refletem-se na desejabilidade social dos idosos de demonstrarem que são autônomos e independentes como justificativa para negação do seu próprio envelhecimento.

Como menciona Geertz (1989), faz-se necessário conhecer o sentido atribuído às coisas na vida em sociedade, uma vez que o valor simbólico que tal construto adquire na atualidade não é algo dado, concerne a uma construção sociocultural e simbólica daquela cultura. Este autor considera a cultura como um universo de significados que permite aos indivíduos de determinado grupo interpretar a própria experiência e guiar suas ações, de modo que a cultura é um vetor na construção das percepções, emoções e intervenções.

Faz-se necessário que a Psicologia Social tenha como princípio básico a observância e escuta, de modo a poder compreender com lucidez os fenômenos psicossociais tais como se encontram no mundo simbólico e significativo das pessoas e dos grupos (Guareschi, 2004). Nesta pesquisa, os discursos dos atores sociais atribuem à velhice um valor simbólico impregnado de estereótipos negativos nas suas representações sociais.

\section{Classe 3: fortalecimento nos aspectos sócio- afetivos advindos da participação nos GC's}

O número de u.c.e. que compõe esta classe foi de 24 $(21,43 \%)$. As variáveis descritivas predominantes nesta classe são idosos na faixa etária de 60 - 65 anos (10 u.c.e.) e do sexo feminino, sendo que as idosas pertencem majoritariamente aos Grupos de Convivências para Idosos.

A noção central desta classe de RS organizou-se em torno dos conteúdos relacionados à velhice percebida nos GC's, a saber: vai, velhas, idade, terceira, anos, cabeça, velho, começa, grupos, sessenta, ginástica, dança. Como se pode perceber, de acordo com as unidades de contexto elementar (u.c.e.) que mais caracteriza esta classe 3, nos conteúdos semânticos a seguir:

(...) A velhice depende muito da cabeça de cada um, a gente tem que ser ativo, fazer novos amigos, passear, participar dos grupos da terceira idade (...) por isso que esses grupos da terceira idade é uma benção, 
se não ficar isolado, vai ter um aproveitamento muito melhor, (...) aqui na melhor idade é que a gente se diverte, dança, é outra vida, sabe, agora se você se entrega é que você vai sentir a velhice, eu encaro a vida normal, me sentindo nova, não tenho que me preocupar porque estou velha (...) esse movimento que a gente vai fazendo aqui ajuda muito na velhice, é muito bom, eu melhorei muito (...), eu sentia dores, sabe, quando levantava, doía as pernas, o braço, a coluna, mas depois que eu comecei a fazer essa ginástica (...) (Entrevista 40, Idoso de GC's).

Neste agrupamento, pode-se verificar que as representações sociais foram objetivadas no fortalecimento dos aspectos sócio-afetivos advindos da participação nos GC's, fato também verificado de forma semelhante nos dados apreendidos em pesquisa realizada sobre representações sociais da velhice entre idosos paraibanos (Araújo, Coutinho \& Saldanha, 2005; Araújo, 2006). Denota-se também que esta classe foi constituída, sobretudo, por idosas que mencionam que a velhice trouxe liberdade e independência para participar das atividades sócio-recreativas executadas nos grupos de convivências.

De forma semelhante ao presente estudo, Lima (1997) verificou RS entre idosos de GC's pernambucanos que atuam como instrumento de enfrentamento contra as questões relacionadas ao envelhecimento físico (perda do vigor físico). Entre esses sujeitos, é fortalecido o sentimento de pertencimento a um grupo que compartilha representações de uma velhice bem-sucedida, tendo como princípio a construção de amizades e amor entre os velhos integrantes dos GC's.

Esta autora ainda ressalta que a interação entre os idosos possibilita mudanças grupais que minimizam os inconvenientes advindos do processo de envelhecimento, bem como ocasiona uma construção da identidade grupal relacionada à idade, velhice e aos mecanismos de apoio social.

É válido salientar que tais representações sociais acerca da velhice também foram verificadas nos grupos de convivência em estudo realizado por Araújo e Carvalho (2004), no qual os idosos objetivaram a velhice comoalgo positivo em sua vida, locus que propicia empoderamento para o exercício da cidadania nesta fase da vida.

Costa e Campos (2003) realizaram pesquisa com idosos que participam de GC's que mencionaram a importância de atividades como: dança, natação, ginástica, bem como o fato de que, nestes grupos, poderem fazer novas amizades e desfrutar de momentos de lazer.

Na presente pesquisa, foi verificada ênfase nas atividades sócio-recreativas, posto que muitos destes idosos mencionavam nas entrevistas que, durante a fase adulta, não puderam participar de atividades integrativas, tendo apenas agora, na velhice, esta oportunidade proporcionada no âmbito dos GC's.
De acordo com Lehr (1996), o abrupto processo de envelhecimento que caracteriza a sociedade contemporânea ocasiona novas percepções sobre estilos e condições de vida, de modo que a manutenção do bem-estar convertese em meta e numa tarefa individual e social prioritária.

Desta forma, envelhecer é tanto um processo individual e subjetivo como envelhecimento social, sendo este um processo universal, de modo que a participação em grupos com pessoas da mesma idade, com os mesmos objetivos, possibilita uma construção de uma representação em que se acentuam os aspectos positivos da velhice (GognalonsNicolet, 1996; Araújo, Coutinho \& Carvalho, 2005; Araújo, Coutinho \& Saldanha, 2005; Araújo, 2006), fato ocorrido quando os idosos mencionam que a aceitação da velhice está na "cabeça”, atribuindo ao papel de cada pessoa (dimensão individual), mas o GC's (dimensão social) pode desenvolver formas de conviver com as perdas e ganhos inerentes à velhice.

Como menciona Moragas (1999), o processo de envelhecimento da população mundial com independência, autonomia e conseqüente qualidade de vida, pode ser uma das inovações do terceiro milênio. Assim, faz-se necessária atenção especial do poder público e das instituições de pesquisas/intervenções no sentido de oferecer serviços que contribuam para uma velhice bem-sucedida, ativa e com autonomia.

Em síntese, nesta pesquisa podem-se elucidar algumas facetas que compõem a construção psicossocial da velhice. Deste modo, os elementos que participam na construção ideológica, psicossocial e cultural da velhice e do processo de envelhecimento, apreendidos entre os idosos pesquisados, são determinados de certa maneira pelo modelo dominante (sociedade capitalista e individualista), que influencia de forma direta as representações sociais da velhice.

\section{Considerações finais}

A presente pesquisa versou sobre as representações sociais da velhice, de forma comparativa entre idosos participantes de instituições de longa permanência e grupos de convivências. Os dados apreendidos entre os idosos possibilitaram representações comuns aos dois grupos e particularidades de acordo com a sua inserção psicossocial, sócio-afetiva e cultural.

Os dados obtidos revelaram que os idosos participantes deste trabalho objetivaram suas representações sociais da velhice no binômio velhice-doença, caracterizando a velhice como algo negativo, portanto, assumindo uma conotação negativa da mesma. Verificou-se também que os grupos vivenciam seu processo de envelhecimento em pólos antagônicos. Se, por um lado, os idosos de grupos de convivências participam de atividades que envolvem aspectos sócio-recreativos, valorização do exercício da 
cidadania e de elucidações concernentes à promoção em saúde, em outro pólo os idosos de instituições de longa permanência vivenciam seu processo de envelhecimento num confinamento sócio-afetivo, devido às caracterizações da institucionalização da velhice.

Apesar das ILPI's serem representadas como um locus importante e necessário para as pessoas idosas que não possuem familiares, são consideradas, muitas vezes, a única "alternativa" viável para preservar mecanismos de sobrevivência, diante das dificuldades socioeconômicas, afetivas e familiares. Por outro lado, percebe-se pelas falas dos participantes a necessidade de uma efetiva reforma político-social dessas instituições, uma vez que elas vêm funcionando como depósito para o confinamento social e afetivo, o que torna a velhice sinônimo da espera/preparação apenas para a morte, de modo que não há a participação dos idosos em atividades sócio-recreativas, tornando-se quase inexistente a sua rede de apoio social.

Uma questão que merece destaque diz respeito à alusão da relação causal existente entre as dimensões divinas/religiosas e o conseqüente processo de envelhecimento. Foi verificada entre os idosos uma prerrogativa para situação/manutenção atual vivenciada na velhice concernente à vontade de Deus. Assim, pode-se formular a seguinte questão: será que tal atribuição divina não é uma resolução da dissonância gerada pelo abandono familiar e social na velhice? É uma questão que merece futuras investigações sob o escopo psicossocial.

Sugere-se que esta pesquisa possa subsidiar e orientar as práticas cotidianas dos profissionais gerontólogos, no que diz respeito às informações psicossociais e programas de educação em saúde relativa a uma imagem positiva do envelhecimento junto às instituições geriátricas, à mídia e aos familiares. É possível que tais profissionais confrontem os estereótipos negativos e os mitos com a possibilidade de um envelhecimento ativo com independência e autonomia.

\section{Referências}

Alba, M. (2004). El Método ALCESTE y su aplicación al estudio de las Representaciones Sociales del Espacio Urbano: El caso de la Ciudad de México. Papers on Social Representations, 13(1), 01-20.

Alcântara, A. O. (2004). Velhos Institucionalizados e Família: entre abafos e desabafos. Alínea: Campinas-SP.

Araújo, L. F. \& Carvalho, V.A M. (2004). Velhices: estudo comparativo das representações sociais entre idosos de grupos de convivências. Textos sobre Envelhecimento, 1(6), 10-22.

Araújo, L. F.; Coutinho, M. P. L. \& Carvalho, V. A M. L. (2005). Representações Sociais da Velhice entre Idosos que Participam de Grupos de Convivência. Psicologia: Ciência e Profissão, 25(1), 118-131.

Araújo, L. F.; Coutinho, M. P. L. \& Saldanha, A. A. W. (2005). Análise comparativa das representações sociais da velhice entre ido- sos de Instituições Geriátricas e Grupos de Convivências. Psico, Porto Alegre-RS, 36( 2), 197-204.

Araújo, L. F.; Coutinho, M. P. L. \& Santos, M. F. S. (2006). Análise Psicossocial do Idoso em Instituições Gerontológicas. Em D. V. S. Falcão \& C. M. S. B. Dias (Org.). Maturidade e Velhice: Pesquisas e Intervenções Psicológicas (pp. 131-150). Casa do Psicólogo: São Paulo.

Araújo, L. F. (2006). Representações Sociais da Velhice: Um estudo comparativo entre idosos de instituições de longa permanência e grupos de convivências. Dissertação de Mestrado em Psicologia Social. Universidade Federal da Paraíba, Departamento de Psicologia, João Pessoa, PB.

Beltrão, K. I. \& Camarano, A. A. (2002). A dinâmica populacional brasileira e a previdência social: uma descrição com ênfase nos idosos. Referência obtida via base de dados Biblio: IPEA. Acessado em 21/01/2002 de http://www.prodepa.gov.br/ sespa/variedades_textos_din.htm.

Camargo, B. V. (2005). ALCESTE: Um programa informático de análise quantitativa de dados textuais. Em A. S. P. Moreira; J. C. Jesuíno \& B. V. Camargo (Org.). Perspectivas teórico-metodológicas em representações sociais (pp. 511-539). EdUFPB: João Pessoa.

Conselho Nacional de Saúde (1996). Resolução para pesquisa envolvendo seres humanos. Resolução 196/96, Brasília.

Conselho Federal de Psicologia (2000). Resolução para pesquisa com seres humanos. Resolução 016/2000, Brasília.

Costa, F. G \& Campos, P. H. F. (2003). Práticas Institucionais e Representações da Exclusão na Terceira Idade. Em P. H. F. Campos \& M. C. S. Loureiro (Orgs.). Representações Sociais e Práticas Educativas (pp. 187-207), Goiânia-GO: EdUCG.

Debert, G. G. (1988). Envelhecimento e Representação da Velhice, Ciência Hoje, São Paulo, 8(44), 60-68.

Debert, G. G. (1998). A antropologia e o estudo dos grupos e das categorias de idade. Em Barros, M. M. L. (Org.). Velhice ou Terceira Idade? Estudos sobre identidade, memória e política (pp. 49-67). São Paulo-SP: FGV.

Debert, G. G. (1999). A reinvenção da Velhice. São Paulo-SP: FAPESP.

Doise, W. (1990). Les représentations sociales. Em Ghiglione, R.; Bonnet, C.\& Richard; J. F.(Eds.). Traité de Psychologie Cognitive, 3, 190-198.

Estatuto do Idoso (2003). Lei no 10.741 de 01 de Outubro de 2003. Brasília-DF: Senado Federal.

Geertz, C. (1989). A Interpretação das Culturas. Rio de Janeiro-RJ: LTC.

Gognalons-Nicolet, M. (1996). Desarollo, Envejecimiento y Realización Personal. Em J. Buendía (Org.). Envejecimiento y Psicología de la Salud (pp. 35- 51). Madrid:Siglo XXI.

Gómez, L. R. (2002). Envejecer en Chiapas: etnogerontología zoque. Instituto de Estudios Indígenas - UNAM:Chipas - México.

Graeff, L. (2005). O "mundo da Velhice" e a cultura asilar: Estudo antropológico sobre memória social e cotidiano de velhos no asilo Padre Cacique, em Porto Alegre. Dissertação de Mestrado em Antropologia Social. Universidade Federal do Rio Grande do Sul, Instituto de Filosofia e Ciências Humanas, Porto Alegre, RS.

Guareschi, P. (2004). Psicologia Social Crítica: como prática de libertação. Porto Alegre: EDIPUCRS.

Hewstone, M. (2001). Representações Sociais e Causalidade. Em D. Jodelet (Org.) As Representações Sociais (pp 217- 237). Rio de Janeiro: EdUERJ. 
Jodelet, D. (1989). Representações Sociais: fenômeno, conceito e teoria. Paris: Presses Universitares de France.

Jodelet, D. (2001). As Representações Sociais. Rio de Janeiro: EdUERJ.

Lehr, U. (1996). La Calidad de Vida de la Tercera Edad: una labor individual y social. Em J. Buendía (Org.). Envejecimiento y Psicología de la Salud (p. 353- 371). Madrid: Siglo XXI.

Lima, D. A Q. (1997). Além do apenas velho: aspectos sócio-culturais da velhice. Dissertação de Mestrado. Universidade Federal da Paraíba, Departamento de Ciências Sociais, João Pessoa, PB.

Moragas, R. (1999). El reto de la independencia al envejecer. Barcelona: Herder.

Moscovici, S. (1961). A Representação Social da Psicanálise. Rio de Janeiro: Zahar.

Moscovici, S. (2001). Das Representações Coletivas às Representações Sociais: elementos para uma história. Em: D. Jodelet (Org.) As Representações Sociais (pp 45-66). Rio de Janeiro: EdUERJ.

Moscovici, S. (2003). Representações Sociais: investigações em psicologia social. Petrópolis-RJ: Vozes.

Neri, A. L. (1993). Qualidade de Vida na Idade Madura. Campinas: Papirus.

Neri, A. L. \& Freire, S. A. (Org.) (2000). E porfalar em boa velhice. Campinas: Papirus.

Neri, A L. (2002). Teorias Psicológicas do Envelhecimento. Em E. V. Freitas \& Cols. (Orgs.) Tratado de Geriatria e Gerontologia, (pp. 32-45), Rio de Janeiro-RJ: Guanabara Koogan.

OMS (2005). Envelhecimento Ativo: uma política de saúde. Brasília: Organização Pan-Americana da Saúde.

Peixoto, C. (1998). Entre o estigma e a compaixão e os termos classificatórios: velho velhote, idoso terceira idade. Em M. L. de Barros (org.), Velhice ou Terceira Idade?(p.15-17). Rio de Janeiro: Fundação Getúlio Vargas.

Política Nacional do Idoso (1998). Programa Nacional de Direitos Humanos. Secretaria Nacional dos Direitos Humanos. Poder Executivo. Ministério de Justiça. Brasília, DF.

PNAD-Pesquisa Nacional porAmostra de Domicílios-IBGE(2003). Rio de Janeiro: RJ, CD-ROM.

Reinert, M. (1986). Un Logiciel d'analyse lexicale: ALCESTE. Les Cahiers de l'analyse des Données, 4, 471-484.

Reinert, M. (1990). Alceste: une methologie d'analyse dês donnees textualles et une application. Em A G. Neval. Bulletin de Méthodologie Sociologique, Paris, 28, 24-54.

Rodríguez, A (1996). Dimensiones Psicosociales de la Vejez. Em J. Buendía (Org.). Envejecimiento y Psicología de la Salud (pp. 53-68). Madrid:Siglo XXI.

Santos, M. F. S. (1994). Velhice ideal? Estudo da Representação Social da Velhice na Zona Rural. Anais da II Conferência Inter- nacional sobre representações sociais. Rio de Janeiro-RJ.

Santos, M. F. S. (1997). O idoso e a Família. Relatório de pesquisa apresentado ao CNPq. Recife, PE.

Santos, M. F. S. \& Belo, I. (2000). Diferentes modelos de velhice. Psico, Porto Alegre, 31, 31-48.

Santos, M. F. S. \& Almeida, A. M. O. (2004). Práticas sociais relativas ao idoso. Temas de Psicologia, Ribeirão Preto, 10 (3), 221-228.

Ludgleydson Fernandes de Araújo é psicólogo, mestre em Psicologia Social/Especialista em Gerontologia/Professor do Departamento de Psicologia da Universidade Federal do Piauí UFPI/Pesquisador do Núcleo de Pesquisa: Aspectos Psicossociais de Prevenção e Saúde Coletiva/Universidade Federal da Paraíba, Endereço: Rua Antônio Leopoldo Batista, 172, Apto 306, Ed. Ibirapuera, Bairro Bancários CEP: 58051-110, João Pessoa-PB.

ludgleydson@yahoo.com.br

Maria da Penha de Lima Coutinho é professora com Pós-Doutorado em Psicologia pela Universidade Aberta de Lisboa-Portugal/Programa de Pós-Graduação em Psicologia Social e Coordenadora do Núcleo de Pesquisa: Aspectos Psicossociais de Prevenção e Saúde Coletiva - UFPB. penhalcoutinho@bol.com.br

Maria de Fátima de Souza Santos é professora do Departamento de Psicologia / Programa de Pósgraduação em Serviço Social da Universidade Federal de Pernambuco. mfsantos@ufpe.br

\section{O idoso nas instituições gerontológicas: um estudo na perspectiva das representações sociais}

Ludgleydson Fernandes de Araújo, Maria da Penha de Lima Coutinho e Maria de Fátima de Souza Santos Recebido: 18/01/2006

Revisão: 10/07/2006

Aceite Final: 10/07/2006 